Article

\title{
Parents ASSIST: Acceptability and Feasibility of a Video-Based Educational Series for Sexuality-Inclusive Communication between Parents and Gay, Bisexual, and Queer Sons
}

\author{
Dalmacio D. Flores ${ }^{1, *(\mathbb{D})}$, Kate Hennessy ${ }^{1}$, Andre Rosario ${ }^{1}$, Jamie Chung ${ }^{1}$, Sarah Wood ${ }^{2}$, Trace Kershaw ${ }^{3}$, \\ Antonia Villarruel ${ }^{1}$ and Jose Bauermeister ${ }^{1}$ (D) \\ 1 Department of Family and Community Health, University of Pennsylvania, Philadelphia, PA 19104, USA; \\ khenn@nursing.upenn.edu (K.H.); arosario@nursing.upenn.edu (A.R.); jamiechung224@gmail.com (J.C.); \\ amvillar@nursing.upenn.edu (A.V.); bjose@nursing.upenn.edu (J.B.) \\ 2 Craig A. Dalsimer Division of Adolescent Medicine, Children's Hospital of Philadelphia, \\ Philadelphia, PA 19104, USA; woodsa@chop.edu \\ 3 Department of Social and Behavioral Sciences, Yale School of Public Health, New Haven, CT 06510, USA; \\ trace.kershaw@yale.edu \\ * Correspondence: dalmacio@nursing.upenn.edu
}

check for updates

Citation: Flores, D.D.; Hennessy, K.; Rosario, A.; Chung, J.; Wood, S.; Kershaw, T.; Villarruel, A.;

Bauermeister, J. Parents ASSIST: Acceptability and Feasibility of a Video-Based Educational Series for Sexuality-Inclusive Communication between Parents and Gay, Bisexual, and Queer Sons. Int. J. Environ. Res. Public Health 2022, 19, 379. https:// doi.org/10.3390/ijerph19010379

Academic Editor: Paul B.

Tchounwou

Received: 22 November 2021

Accepted: 26 December 2021

Published: 30 December 2021

Publisher's Note: MDPI stays neutral with regard to jurisdictional claims in published maps and institutional affiliations.

Copyright: (c) 2021 by the authors Licensee MDPI, Basel, Switzerland. This article is an open access article distributed under the terms and conditions of the Creative Commons Attribution (CC BY) license (https:// creativecommons.org/licenses/by/ $4.0 /)$.

\begin{abstract}
Young men who have sex with men (YMSM) between the ages of 13 and 24 are a key population for HIV prevention. The parents of gay, bisexual, and queer (GBQ) adolescent males and the sex communication they have with their sons has yet to be explored as an HIV prevention intervention. We developed an online video series called Parents ASSIST (Advancing Supportive and Sexuality-Inclusive Sex Talks) to educate parents about sexual health topics pertinent to GBQ males. We pilot tested the series with a sample of 54 parents of GBQ males using a single-group post-test design. Participants viewed the videos and completed a survey measuring the acceptability and feasibility of an online video series to educate parents. Most of the parents $(70.4 \%)$ believed that the videos would make parents more likely to initiate talking about sex with their sons. The results suggest that online videos are an acceptable way for parents to learn about GBQ sexual health topics.
\end{abstract}

Keywords: HIV prevention; online intervention; MSM

\section{Introduction}

HIV and STIs disproportionately affect gay, bisexual, and queer (GBQ) adolescent males. In 2018, GBQ adolescent males accounted for $92 \%$ of new HIV diagnoses among all 13- to 24-year-olds, and 21\% of new HIV diagnoses among all gay, bisexual, and queer male age groups [1]. Racial HIV disparities remain salient within this population, with Black and Latinx GBQ adolescent males disproportionately affected by HIV diagnoses [2]. Sexual risk behaviors, including condomless intercourse, early debut, and forced sex, are also more prevalent among GBQ adolescent males compared to their heterosexual counterparts [3]. Sexual risk behaviors are also associated with negative mental health in GBQ adolescent males [4]. The hostile and non-accepting ecological structures in which GBQ youth often operate are linked to negative mental health outcomes including higher reports of depression, suicidal ideation, and emotional distress compared to their heterosexual counterparts [3,5]. For instance, $40 \%$ of GBQ adolescent males stated that they had seriously considered suicide, compared to $11 \%$ of their heterosexual counterparts [5].

Despite the negative outcomes noted, LGBTQ youth, including GBQ adolescent males, report earlier ages for self-identification and for coming-out compared to prior LGBTQ generations [6]. A 2021 Gallup poll reported an increase in the number of U.S. adults identifying as LGBTQ from $4.5 \%$ in 2017 to $5.6 \%$ in 2020 [6]. This increase may be linked to 
growing acceptance of same-sex relationships and sexual behaviors in society [7]. Generation Z, or those born between 1997 and 2012, includes the greatest proportion of LGBTQidentifying individuals [6]. Among a national sample of gay and bisexual men in the U.S., Grov et al. (2018) found that a vast majority (83.6\%) of those sampled reported having their first same-sex attractions at an average age of 10.4; the average age that GBQ men reported having told someone about their identity was 17.9 [8]. Earlier disclosure of sexual identity may afford more opportunities to provide LGBTQ youth with inclusive information, that is, sexuality-specific support and education. In turn, this support and education can impact GBQ adolescent males' behavior and act as health-protective factors. Ecological determinants, including parental communication, can function as health-protective factors, given the proximal relationship parents have with GBQ youth.

Parents are in an opportune position to serve as sexuality information and support providers for their LGBTQ children [9]. Parents are able to communicate with children before sexual debut [10] and educate and support LGBTQ teens as they become aware of their attractions, behaviors, and identities [11]. As shown in our previous work, GBQ males in the Southern U.S. have expressed wanting to learn about sexual health from their parents rather than from other sources such as health-care providers, teachers, or the internet [12]. Underscoring their unique same-sex attractions and experiences that are different from cisgender sexual diverse females (lesbian, queer, etc.) and gender diverse youth (transgender, gender nonbinary, etc.), GBQ males contend with incessant homophobia and navigate oppressive and homophobic systems that ignore their emerging sexual health education needs $[13,14]$. Family relationships have been shown to impact the sexual behaviors of LGBT youth through close relationships and through conversations about being cautious and using condoms [15].

Effective sex communication at home improves heterosexual adolescents' self-efficacy with condom use, skills to resist pressure to have sex, readiness to initiate conversations about HIV /STI prevention before engaging in sex with partners, and use of reproductive and sexual health services [16-21]. Sex communication between mothers and adolescents in particular demonstrates a protective role resulting in safer sex behavior among adolescents [21]. Parent-child sex communication is associated with later sexual initiation, less at-risk sex behavior, and increased condom use in adolescence [22,23]. While past research offers a list of evidence-based interventions for sex communication between heterosexual adolescents and their parents [16], there is a dearth of interventions for sex communication involving parents with non-heterosexual children, including parents of GBQ adolescent males [11,24,25]. To our knowledge, despite 40 years of PCSC research, there is no published intervention focused on parents with LGBTQ youth. Recent literature reviews have similarly reported the lack of GBQ-specific intervention work that aims to address the sexual health outcomes of this subpopulation $[9,21,26]$. Further, GBQ youth face unrelenting standards of hegemonic masculinity as they come of age [12] and have an array of sexual health concerns that differ markedly from those of their heterosexual counterparts, making modifications to current interventions for heterosexual adolescents particularly challenging for GBQ youth.

Parental acceptance and sexuality-specific support are linked to feelings of affirmation and fewer identity struggles for LGBTQ individuals [27], while family rejection or lack of support is associated with negative sexual and mental health outcomes [28,29]. Morris et al. (2020) found that among GBQ adolescent males from three major urban U.S. cities who were living with parents or guardians, those whose mothers had provided accepting spaces and positive reactions to disclosures of sexual identity were less likely to engage in sexual risk behaviors [30]. Family support was also protective in terms of reducing the prevalence of reporting four or more sexual partners in the previous 12 months [4].

Parents of LGBTQ youth are not only well-positioned to provide support to their children on health-related topics, but they are also eager to do so. Rose et al. (2014) found that $90 \%$ of parents reported that health communication was moderately to very important to them, highlighting feelings of connectedness as a major benefit [31]. Many parents view 
sex communication with their GBQ sons as part of their parental responsibility even when their sons resist or are uncomfortable [32]. This drive to communicate about engaging in safer sex demonstrates the further positive impact that parents can have on sexual health outcomes for GBQ sons when parents are given relevant information and tools.

Previous work has found that parents describe sex communication as interactive discussions, while GBQ sons describe their conversations as vague; the direction they receive about safer sex is often too broad or lacks information specific to their sexual identities [15]. Parents give the same advice to their heterosexual children as they do to their non-heterosexual children [33], indicating discomfort or a lack of knowledge around sex topics relevant to GBQ adolescent males [15,34,35]. During sex communication, African American parents and GBQ sons report that HIV and sexual orientation are the most discussed topics [31], which may be driven by fear, lack of specific sexual health knowledge, or discomfort with other topics such as sexual activity. LaSala (2015) also found from a diverse racial/ethnic sample that GBQ adolescent males report that they are waiting for their parents to initiate sex communication, while at the same time, parents are expecting their sons to be the ones to initiate conversation [15]. This misalignment in expectations creates a gap in communication and prevents successful initiation of sexuality-focused parent-child sex communication.

These reported inadequacies signal opportunities to improve sex communication between parents and their GBQ sons. Other parent-reported barriers to sex communication with GBQ sons have included a lack of accurate knowledge, effective peer-parental role models to emulate, and confidence to initiate and sustain conversations about sex $[9,24]$. Parental discomfort and feelings of ineptitude around discussing sex can impede discernible research findings on the effectiveness of parent-child sex communication for GBQ sons [36]. Equipping parents of GBQ adolescent males with the tools and knowledge to initiate and sustain sex communication will allow for a clearer picture of the protective role that parent-child sex communication plays in health outcomes for GBQ sons as well as the effectiveness of sex communication interventions for this population.

The Parents ASSIST (Advancing Supportive and Sexuality-Inclusive Sex Talks) video series was designed to be an online resource for parents to (1) learn about the pertinent sexual health topics germane to GBQ youths' sexuality concerns and (2) receive communication skills for initiating and sustaining sex discussions with GBQ sons. The Theory of Planned Behavior (TPB) and Social Cognitive Theory (SCT), which have been used as frameworks to influence parents' intentions to communicate about sexual health in previous research $[21,37]$, serve as the theoretical backbones of our video content. TPB rests on the idea that an individual's attitudes, subjective norms, and perceived behavioral control influence that individual's intention to perform a behavior $[38,39]$, including the intention to communicate about inclusive sexual health with a GBQ son.

To address parental attitudes, or positive or negative beliefs about a behavior, the videos prompt parents to examine their attitudes toward more inclusive sex talks and to reflect on personal experiences with sex communication with their own parents. The videos aim to support parents' positive attitudes about health issues pertinent to GBQ sons' identities. To address subjective norms or perceived social influences to engage or not engage in a behavior, the videos reference other parents' normative beliefs about sex communication from larger, heteronormative ecological systems around the home [12]. The main characters of the video series include parents who share their similar concerns and situations. Regarding perceived behavioral control, or one's self-efficacy to perform a behavior, the videos prompt parents to examine their capacity to initiate and sustain inclusive talks. Social Cognitive Theory (SCT) posits that by observing others perform a behavior, including inclusive sex communication, individuals learn to engage in that behavior [40]. The videos capitalize on observational learning by modeling inclusive sex communication, normalizing parental hesitance to address sex with GBQ sons, and encouraging frequent attempts to engage GBQ sons. Our primary aims for this Parents ASSIST pilot study were to (1) determine the feasibility of enrolling parents of GBQ youth into an 
online study about targeted sexual health discussions at home, (2) measure the acceptability of animated videos as a means to learn about GBQ-specific topics and communication skills, and (3) collect parental feedback about individual video content and the overall video series.

\section{Methods}

\subsection{Intervention Description}

The Parents ASSIST project is an online series of 13 animated videos. For this pilot study, the videos were presented on a website that also described the study aims, listed the study team members, and offered additional online resources for sexual health information. The central video in this series, "Answering Questions", runs for $12 \mathrm{~min}$, and the remaining 12 videos range from 4 to $6 \mathrm{~min}$ in length. The cast of animated characters represents people from different cultural backgrounds through dress, gender, ethnicity, and age, as well as through situations that reflect common and shared parenting concerns across diverse populations. Previous research has found that culturally tailored eHealth videos could be used to increase awareness of HIV/STI prevention methods since the viewers may identify with the characters, which lessens their resistance to the health message [41-43]. In addition, Bandura (2001) recommended that characteristics of the models should be similar to the viewers' to increase the impact of educational modeling [40]. Aside from the racially and ethnically diverse animated characters, the Parents ASSIST videos feature at least 48 sexual health topics and a multitude of family contexts to ensure its appeal to our target participants.

\subsection{Intervention Development Procedures}

We worked alongside community members to develop the video series [13]. The initial framework for the videos was established using recollections from GBQ sons who reported salient issues in parent-child sex communication [12,44]. Using that foundation, advisory groups were formed. First, a Parent Advisory Board was assembled. It was comprised of parents of GBQ cisgender males, school educators who identified as gay, and health-care professionals with LGBTQ health experience. We explored their thoughts about existing resources, determined their intervention priorities, and identified any logistical concerns around intervention work with the target population. The Parent Advisory Board members suggested that a video-based intervention would appeal to other parents and be a convenient way to learn about sexual health topics and communication strategies. Over the course of a year, they met four times to select video topics that appealed to parents and to evaluate how relatable and realistic the video scripts appeared. Ultimately, the Parent Advisory Board guided screenplay development for the videos, provided content expertise, and helped ensure that the topics recommended by GBQ youth were included throughout the development of the intervention [13].

Second, an Interdisciplinary Group of Nurses and Health Educators (IGNHE) was convened to ensure that the videos presented clinically reliable information. Members included pediatricians, public health researchers, an AIDS-certified nurse, and a sexual health educator. They offered feedback on the scripts being developed by the parents. The combined feedback from groups of health-care professionals and parents contributed to multiple stages of developing the videos, website, and study procedures. During subsequent meetings, advisory group members provided their suggestions on the quality of the animated characters' voices, the conversations between central characters, and the overall appeal of the videos. This cyclical engagement that lasted for over a year starting in 2018 between advisory group members and program staff enabled the iterative codevelopment and refinement of a theoretically-driven video series and website cognizant of the unique parenting challenges that our target audience faces. The iterative process of organizing these groups and integrating their feedback into different stages of developing the intervention has been detailed elsewhere [13]. 


\subsection{Participant Recruitment}

Once the videos and website were developed, we recruited an online sample of English-speaking parents whose GBQ sons were between the ages of 12 and 24 years to participate in online surveys. Participants were recruited nationally through advertisements on Facebook and through word-of-mouth from community organizations local to Philadelphia. Advertisements directed at children to recruit their parents were approved by our Institutional Review Board. Eligibility criteria included having a male son between the ages of 12 and 24 years old who identified as gay, bisexual, or queer. As an incentive, participants were offered a $\$ 50$ Amazon gift card.

\subsection{Study Procedures and Measures}

Eligible participants first completed an online consent form. Then, they watched 3 videos from the series. Afterwards, a post-test survey was conducted. The survey also allowed participants to write free-text comments. The survey measured acceptability and feasibility along the following dimensions: relatability, likeability, utility, recommendability, realistic quality, and potential impact (Table 1). After survey data collection was completed, 6 parents (about $10 \%$ of the sample) who provided the highest and lowest survey ratings were contacted for a chance to view the remaining Parents ASSIST videos they had not seen and to participate in a one-on-one interview.

Table 1. Project Dimensions and Sample Survey Questions.

\begin{tabular}{|c|c|}
\hline Dimension & Survey Question \\
\hline Relatability & $\begin{array}{l}\text { Q1. Could you relate to the characters? } \\
\text { Q2. How interesting were the videos you watched? } \\
\text { Q3. Would you describe their situations as realistic? }\end{array}$ \\
\hline Likeability & $\begin{array}{l}\text { Q4. Did you like what the main characters were saying? } \\
\text { Q5. Do you think other parents might like to see the videos? } \\
\text { Q6. How much did you like the video series you just watched? }\end{array}$ \\
\hline Utility & $\begin{array}{l}\text { Q7. Do you think that watching the videos could help increase parents' } \\
\text { knowledge about their sons' health and sexuality questions? } \\
\text { Q8. Do you think the videos you watched could make it more likely that other } \\
\text { parents will seek further information about LGBTQ health and sexuality? } \\
\text { Q9. Did the videos add to your learning about LGBTQ health and } \\
\text { sexuality issues? } \\
\text { Q10. How much new information did you learn as a result of the videos you } \\
\text { just watched? }\end{array}$ \\
\hline Recommendability & $\begin{array}{l}\text { Q11. Would you recommend the animated videos to other parents of gay, } \\
\text { bisexual, or queer adolescent males? } \\
\text { Q12. Would you recommend watching these videos with your soon? } \\
\text { Q13. Would you share the videos with your friends? }\end{array}$ \\
\hline Realistic Quality & $\begin{array}{l}\text { Q14. Were the stories realistic? } \\
\text { Q15. Would you describe their situations as realistic? }\end{array}$ \\
\hline $\begin{array}{l}\text { Potential to Impact } \\
\text { Communication }\end{array}$ & $\begin{array}{l}\text { Q16. Do you think that watching the videos could help parents initiate and } \\
\text { sustain sex and health discussions with their gay, bisexual, or queer sons? } \\
\text { Q17. Do you think the videos you watched could make it more likely that } \\
\text { other parents will want to initiate and sustain inclusive parent-child } \\
\text { conversations about health and sexuality? } \\
\text { Q18. Do you think that after watching the videos, parents will be more likely } \\
\text { to initiative inclusive conversations about health and sexuality with their sons? } \\
\text { Q19. Do you think that after watching the videos, parents will be more likely } \\
\text { to sustain inclusive conversations about health and sexuality with their sons? } \\
\text { Q20. Do you think the videos could help parents learn how to handle } \\
\text { conversations about health and sexuality with adolescent sons and broach } \\
\text { issues/questions centered on same-sex attractions or behaviors? }\end{array}$ \\
\hline
\end{tabular}

\section{Findings}

\subsection{Demographic Findings}

Table 2 provides demographic details of the study sample. The parents who participated in our study $(\mathrm{N}=54)$ had a mean age of $44.5(\mathrm{SD}=5.56)$ and included 30 mothers 
$(55.6 \%)$ and 24 fathers (44.4\%). Most participants identified as Caucasian/White $(n=44$, $81.5 \%)$ followed by African American/Black $(n=5,9.3 \%)$. Other participants were Biracial $(n=3,5.6 \%)$, Asian/Pacific Islander $(n=1,1.9 \%)$, or Native American/Alaskan $(n=1$, $1.9 \%)$. The majority of participants identified as Non-Hispanic/Non-Latino $(n=47,87 \%)$.

Table 2. Demographic Profile.

\begin{tabular}{|c|c|c|}
\hline & Frequency $(n=54)$ & Percentage \\
\hline \multicolumn{3}{|l|}{ Parent's Age } \\
\hline $32-40$ & 11 & 20.6 \\
\hline $41-50$ & 35 & 65 \\
\hline $53-60$ & 6 & 11.3 \\
\hline Not specified & 2 & 3.7 \\
\hline \multicolumn{3}{|l|}{ Sex } \\
\hline Male & 24 & 44.4 \\
\hline Female & 30 & 55.6 \\
\hline \multicolumn{3}{|l|}{ Race } \\
\hline Caucasian/White & 44 & 81.5 \\
\hline African American & 5 & 9.3 \\
\hline Asian/Pacific Islander & 1 & 1.9 \\
\hline Native American/Alaskan & 1 & 1.9 \\
\hline Biracial & 3 & 5.6 \\
\hline \multicolumn{3}{|l|}{ Ethnicity } \\
\hline Hispanic/Latino & 7 & 13 \\
\hline Non-Hispanic/Non-Latino & 47 & 87 \\
\hline \multicolumn{3}{|l|}{ U.S. Region } \\
\hline Northeast & 16 & 29.8 \\
\hline South & 13 & 24.3 \\
\hline Midwest & 9 & 16.8 \\
\hline West & 16 & 29.7 \\
\hline \multicolumn{3}{|l|}{ Son's Age } \\
\hline $14-16$ & 26 & 48.1 \\
\hline $17-19$ & 17 & 31.5 \\
\hline $20-24$ & 11 & 20.5 \\
\hline \multicolumn{3}{|l|}{ Son's Grade } \\
\hline 8 th grade & 8 & 14.8 \\
\hline 9th grade & 8 & 14.8 \\
\hline 10th grade & 6 & 11.1 \\
\hline 11th grade & 7 & 13 \\
\hline 12th grade & 9 & 16.7 \\
\hline College/vocational/trade school & 11 & 20.4 \\
\hline Finished college/vocational/trade school & 3 & 5.6 \\
\hline \multicolumn{3}{|l|}{ Son's Sexual Orientation } \\
\hline Gay & 48 & 88.9 \\
\hline Bisexual & 5 & 9.3 \\
\hline
\end{tabular}


Table 2. Cont.

\begin{tabular}{ccc}
\hline & Frequency $(\boldsymbol{n}=\mathbf{5 4})$ & Percentage \\
\hline Queer & 1 & 1.9 \\
\hline Son's Gender & & \\
\hline Cisgender male & 54 & \\
\hline Time Known Son is GBQ & & 5.6 \\
\hline $1-2$ months & 3 & 9.3 \\
\hline $2-6$ months & 5 & 18.5 \\
\hline $6-12$ months & 10 & 29.6 \\
\hline $1-2$ years & 16 & 18.5 \\
\hline $2-4$ years & 10 & 18.5 \\
\hline More than 4 years & 10 & \\
\hline
\end{tabular}

The participants' sons were an average age of $16.98(\mathrm{SD}=2.57)$, with a majority in high school $(n=30,55.6 \%)$, while some were in college/vocational school $(n=11,20.4 \%)$ or middle school $(n=8,14.8 \%)$. Most participants reported that their sons self-identify as gay $(n=48,88.9 \%)$ or bisexual $(n=5,9.3 \%)$ while one had a queer-identifying son $(1.9 \%)$. According to the sample, over one-third of sons had come out more than 2 years ago $(n=20,37 \%)$, and many of them had come out within the past $1-2$ years $(n=16,29.6 \%)$. Some participants reported their sons coming out more recently-about $18.5 \%$ of them $(n=10)$ between 6 and 12 months ago, and another 14.8\% $(n=8)$ within the past 6 months.

\subsection{Feasibility}

Pilot study results show that parents engaged with the Parents ASSIST videos from start to finish. Participants took an average of $41 \mathrm{~min}$ to complete watching the required three videos ("Answering Questions", 1 topic-based video, and 1 communication-based video). The time reflects pausing videos and providing responses to pop-up questions we programmed to capture in-the-moment feedback. The total average time from participants signing consent to the final survey question was 71 min with 52 of the 54 parents completing the online survey in a single sitting.

\subsection{Acceptability}

Table 3 summarizes the survey questions related to six dimensions of acceptability. Regarding relatability, $27.8 \%(n=15)$ of participants agreed that "I definitely related to most or all the characters", while $44.4 \%(n=24)$ could relate to "many of the characters". $20.4 \%$ $(n=11)$ of participants described the series as "extremely interesting", $61.1 \%(n=33)$ as "very interesting", and 14.8\% $(n=8)$ as "moderately interesting". On a question where participants indicated how realistic the videos appeared to them, $75.9 \%(n=41)$ indicated "definitely yes", while $24.1 \%(n=13)$ indicated "maybe", and none indicated "definitely no".

Table 3. Acceptability Measure Results.

\begin{tabular}{|c|c|c|c|c|c|}
\hline \multirow[t]{2}{*}{ Domains * } & \multicolumn{5}{|c|}{ Responses N (\%) } \\
\hline & \multicolumn{4}{|c|}{ Relatability } & \\
\hline \multirow[t]{2}{*}{ Q1. } & $\begin{array}{l}\text { I definitely related to } \\
\text { most or all the } \\
\text { characters }\end{array}$ & $\begin{array}{l}\text { I could relate to many } \\
\text { of the characters }\end{array}$ & $\begin{array}{l}\text { I could relate to some } \\
\text { of the characters }\end{array}$ & $\begin{array}{l}\text { I don't know if I } \\
\text { could relate to any of } \\
\text { the characters }\end{array}$ & $\begin{array}{c}\text { No, I could not relate } \\
\text { to any of the } \\
\text { characters }\end{array}$ \\
\hline & $15(27.8)$ & $24(44.4)$ & $14(25.9)$ & $1(1.9)$ & $0(0)$ \\
\hline \multirow[t]{2}{*}{ Q2. } & Extremely interesting & Very interesting & $\begin{array}{l}\text { Moderately } \\
\text { interesting }\end{array}$ & Slightly interesting & Not at all interesting \\
\hline & $11(20.4)$ & $33(61.1)$ & 8 (14.8) & $2(3.7)$ & $0(0)$ \\
\hline
\end{tabular}


Table 3. Cont.

\begin{tabular}{|c|c|c|c|c|c|}
\hline Domains * & & & Responses N (\%) & & \\
\hline \multirow[t]{2}{*}{ Q3. } & Definitely Yes & Maybe & Definitely No & & \\
\hline & $41(75.9)$ & $13(24.1)$ & $0(0)$ & & \\
\hline \multicolumn{6}{|c|}{ Likeability } \\
\hline \multirow[t]{2}{*}{ Q4. } & Definitely Yes & Maybe & Definitely No & & \\
\hline & 41 (75.9) & $13(24.1)$ & $0(0)$ & & \\
\hline \multirow[t]{2}{*}{ Q5. } & Most or all would & Many would & I don't know & A few would & None would \\
\hline & $15(27.8)$ & $33(61.1)$ & $4(7.4)$ & $2(3.7)$ & $0(0)$ \\
\hline \multirow[t]{2}{*}{ Q6. } & Very much & Somewhat & Neutral & Not much & Not at all \\
\hline & $28(51.9)$ & $22(40.7)$ & $1(1.9)$ & $3(5.6)$ & $0(0)$ \\
\hline \multicolumn{6}{|c|}{ Utility } \\
\hline \multirow[t]{2}{*}{ Q7. } & Definitely Yes & Maybe & Definitely No & & \\
\hline & $47(87)$ & $7(13)$ & $0(0)$ & & \\
\hline \multirow[t]{2}{*}{ Q8. } & Definitely Yes & Maybe & Definitely No & & \\
\hline & $37(68.5)$ & $17(31.5)$ & $0(0)$ & & \\
\hline \multirow[t]{2}{*}{ Q9. } & Definitely Yes & Maybe & Definitely No & & \\
\hline & $36(66.7)$ & $14(25.9)$ & $4(7.4)$ & & \\
\hline \multirow[t]{2}{*}{ Q10. } & A great deal & Some & Little & None & \\
\hline & $32(59.3)$ & $19(35.2)$ & $2(3.7)$ & $1(1.9)$ & \\
\hline \multicolumn{6}{|c|}{ Recommendability } \\
\hline \multirow[t]{2}{*}{ Q11. } & Yes & No & & & \\
\hline & $49(90.7)$ & $5(9.3)$ & & & \\
\hline \multirow[t]{2}{*}{ Q12. } & Yes & No & & & \\
\hline & $46(85.2)$ & $8(14.8)$ & & & \\
\hline \multirow[t]{2}{*}{ Q13. } & Definitely Yes & Maybe & Definitely No & & \\
\hline & $43(73.6)$ & $10(18.5)$ & $1(1.9)$ & & \\
\hline \multicolumn{6}{|c|}{ Realistic Quality } \\
\hline \multirow[t]{2}{*}{ Q14. } & Definitely Yes & Maybe & Definitely No & & \\
\hline & $35(64.8)$ & $19(35.2)$ & $0(0)$ & & \\
\hline \multirow[t]{2}{*}{ Q15. } & Definitely Yes & Maybe & Definitely No & & \\
\hline & $41(75.9)$ & $13(24.1)$ & $0(0)$ & & \\
\hline & & Potential to $\mathbf{I}$ & ommunication & & \\
\hline \multirow[t]{2}{*}{ Q16. } & Definitely Yes & Maybe & Definitely No & & \\
\hline & $38(70.4)$ & $15(29.6)$ & $0(0)$ & & \\
\hline \multirow[t]{2}{*}{ Q17. } & Definitely Yes & Maybe & Definitely No & & \\
\hline & $40(74.1)$ & $13(24.1)$ & $0(0)$ & & \\
\hline \multirow[t]{2}{*}{ Q18. } & Definitely Yes & Maybe & Definitely No & & \\
\hline & $38(70.4)$ & $16(29.6)$ & $0(0)$ & & \\
\hline \multirow[t]{2}{*}{ Q19. } & Definitely Yes & Maybe & Definitely No & & \\
\hline & $37(68.5)$ & $17(31.5)$ & $0(0)$ & & \\
\hline \multirow[t]{2}{*}{ Q20. } & Definitely Yes & Maybe & Definitely No & & \\
\hline & $43(79.6)$ & $11(20.4)$ & $0(0)$ & & \\
\hline
\end{tabular}

* Please refer to Table 1 for the survey questions. 
In measuring likeability, $75.9 \%(n=41)$ of participants indicated "definitely yes" when rating how much they liked what the main characters were saying. In asking participants if they thought other parents might like to see the videos, $27.8 \%(n=15)$ said "most or all would", while the majority indicated "many would" ( $n=33,61.1 \%)$. When asked how much participants liked the video series, 51.9\% indicated the highest rating, "very much" $(n=28)$.

Our survey also measured knowledge utility. When asked if participants thought that watching the videos would help increase parents' knowledge about their sons' health and sexuality questions, the majority indicated "definitely yes" ( $n=47,87 \%)$. When asked if participants thought that the videos could make it more likely that other parents would seek further information about LGBTQ health and sexuality, the majority indicated "definitely yes" $(\mathrm{N}=37,68.5 \%)$. Finally, in asking the participants if the videos added to their learning about LGBTQ health and sexuality issues, two-thirds answered, "definitely yes" ( $n=36$, $66.7 \%)$. Gauging how much new information the participants felt they learned, 59.3\% $(n=32)$ noted they learned "a great deal", while 35.2\% $(n=19)$ reported learning "some" new information.

In terms of recommendability, $90.7 \%(n=49)$ of participants indicated that they would recommend the animated videos to other parents of GBQ adolescent males, while 5 parents indicated "no". Relatedly, $85.2 \%(n=46)$ of participants would recommend watching the videos with their sons. When asked if they would share the videos with their friends, $79.6 \%$ $(n=43)$ indicated "definitely yes". With regards to whether the videos seemed realistic, $64.8 \%(n=35)$ reported "definitely yes". In response to "Would you describe their situations as realistic", $75.9 \%(n=41)$ answered, "definitely yes".

The survey asked questions about the video series' perceived potential to impact communication. When asked if the videos could help parents initiate and sustain sex and health discussions with their GBQ sons, the majority of participants $(n=38,70.4 \%)$ answered, "definitely yes". When asked if the videos would prompt parents to initiate inclusive conversations about health and sexuality with their sons, answers were consistent; $70.4 \%(n=38)$ of participants answered, "definitely yes". When asked if the videos could make it more likely that other parents do the same, $74.1 \%(n=40)$ answered, "definitely yes". We also asked if participants thought the videos could help parents sustain inclusive conversations about health and sexuality with their sons and $68.5 \%(n=37)$ answered, "definitely yes". Finally, we asked participants if they thought that the videos could help parents learn how to handle conversations about health and sexuality with adolescent sons and broach issues/questions centered on same-sex attractions or behaviors. The majority ( $n=43,79.6 \%)$ indicated "definitely yes".

Parents rated the videos using a 6-point scale (1-very poor, 2-poor, 3-fair, 4-good, 5-very good, 6-excellent). They also supplied qualitative feedback via pop-up boxes after each video was viewed in its entirety. The ratings and qualitative feedback for each individual video are listed in Table 4. 
Table 4. Ratings for Each Video and Qualitative Feedback.

Video, Mean Rating,

SD, Range

1-Very Poor to 6-Excellent
Video Descriptions

Qualitative Feedback

\section{Communication-Skills Focused Videos}

Answering Questions

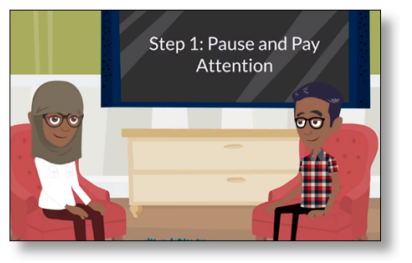

Mean: 4.94 (0.90)

Range: 2-6

Overcoming Communication Barriers

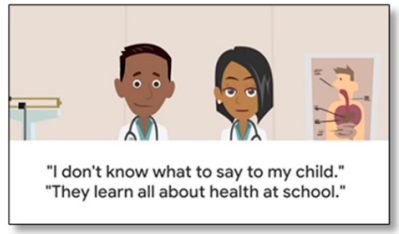

Mean: $4.22(0.98)$

Range: 3-6
Depicts a conversation between a mother and son to demonstrate various verbal and nonverbal techniques that help to provide a nonjudgmental and affirming environment when answering a son's emergent questions. Constructs addressed: Observational Learning; Self-Efficacy/Perceived Behavioral Control. (Duration: 12:14 min)
Nurses address misconceptions about sex communication with children to encourage parents to initiate conversations about sex with their sons. Constructs addressed: Attitudes; Subjective Norms (Duration: 5:00 min)
"This video was great. I learned how to manage emotions and find a proper way to

communicate with my children."

-Claire, mother with a $15 \mathrm{y} / \mathrm{o}$ gay son "I like how it talked about most parents are uncomfortable talking to their kids about sex also how our facial expression can tell a lot and to answer the questions with facts take time to think about the answer."-April, mother of $15 \mathrm{y} / \mathrm{o}$ gay child

"It's such a great topic! It needs to be done much sooner in life ... If our culture could be taught to start talking about their bodies at an early age and age appropriately I think it would prevent a lot of issues surrounding the LQBTQ community and beyond."-Victoria, mother with a $19 \mathrm{y} / \mathrm{o}$ gay son

"It's a great video which made me tear up. I would like to share this video to my family members and friends."-Shawn, father of $14 \mathrm{y} / \mathrm{o}$ gay child guidance on affirmative responses for parents

Constructs addressed: Attitudes; Self-Efficacy/Perceived Behavioral Control (Duration: 4:25 min)
Presents various coming out stories. Provides when sons come out.

Coming Out and Communication Tips

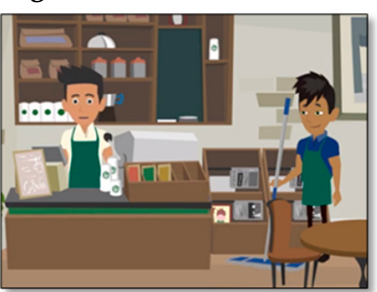

Mean: $5.25(0.89)$

Range: 4-6

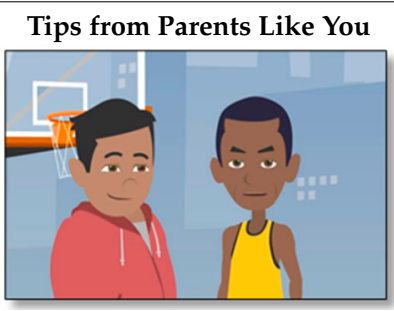

Mean: $5.09(0.70)$

Range: 4-6
You're Normal, Kiddo!

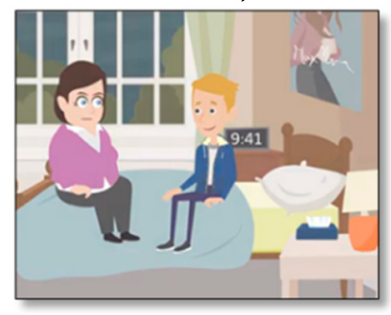

Offers advice on how parents can express their own views about sex in open and inclusive sex communication with their sons.

Constructs addressed: Subjective Norms; Attitudes (Duration: 4:45 min)
"I really liked hearing each of the adolescents stories of how they came out. I know its incredibly hard for a teen when they come out but the video made me realize its even more complex then I originally thought. I liked the way the information was presented and it also motivated me to want to go research more online."-Jack, father of 15 y/o gay child "It's not a easy thing to come out for a teenager. I went through a hard time with my son when he realized he may like a boy." - Tom, father of $15 \mathrm{y} / \mathrm{o}$ bisexual son

"I was so moved by this video, and it's very much like a story that happened in my life."-Joanne, mother with a 15 y/o gay son "It was encouraging to talk to other parents and again see that surrounding yourself with likeminded people is helpful ... I liked how all of the talk was gender and sexuality neutral because all the issues are relevant for all teens, irrespective of gender or sexual orientation."-Robert, father of $19 \mathrm{y} / \mathrm{o}$ gay child

"I had never thought body language was important while talking and I agree with the video-it does make a big difference and is significant. The video made me think about the tone and facial expressions I should be using. I also liked the part that dealt with answering my son's questions with facts that he will understand."-Jack, father with a $15 \mathrm{y} /$ o gay son

Normalizes LGBTQ identities and introduce various sexuality and gender-specific terms. Models parental reassurance of GBQ sons and highlights stigma experienced due to societal heteronormativity.

Constructs addressed: Observational Learning; Attitudes

(Duration: 5:54 min)
Mean: $5.00(0.82)$

Range: 4-6
"The scroll of terms is a reminder how much there is to learn, and how much we are not taught about sexual orientation and gender identity ... I appreciate that the doctor character talked about learning from and along with his children."-Cynthia, mother of 24 y/o gay child 
Table 4. Cont.

\section{Video, Mean Rating, SD, Range \\ 1-Very Poor to 6-Excellent}

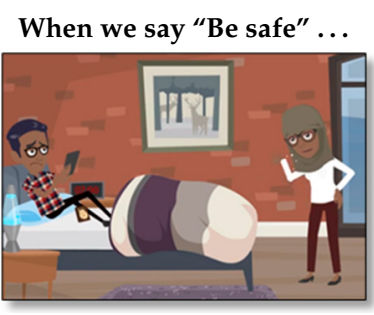

Mean: 4.60 (0.70)

Range: 4-6
Video Descriptions

Qualitative Feedback
Emphasizes importance of ongoing sex communication that is detailed instead of general instructions about safety. Constructs addressed: Attitudes; Self-Efficacy/Perceived Behavioral Control (Duration: 6:20 min)

\section{Setting Rules and the Teenager's}

\section{Developing Brain}

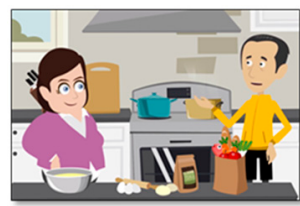

Mean: 5.00 (0.89)

Range: 4-6
Models parental rule-setting that aligns with adolescent brain development. Constructs addressed: Intentions; Observational Learning (Duration: 6:15 min)
"I thought it presented a specific scenario that a parent could use as an example for a conversation about being safe. I like the "fail" examples also. Using humor can be a way to lessen the anxiety that might surround the issue."-Michelle, mother with a 16 y/o queer-identifying child

"It's kind of embarrassing for me to talk with my kids about "safety" since I need to mention a lot of details. They might feel more awkward than me. This video solves the problem perfectly." - Sheena, mother of $14 \mathrm{y} / \mathrm{o}$ gay child
"It's very useful." -Franklin, father of 20 y/o gay child

"The video regarding setting rules and teenagers developing brain did not seem to flow so easy for me. I also didn't feel like that would be normal conversation between a father and a son."-Amy, mother of 22 y/o gay child

Information-Focused Videos

\section{Before Doing the Deed}

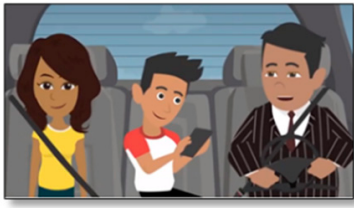

Mean: 4.55 (0.82)

Range: 4-6
Suggests ways parents can provide sex education and gauge their sons' readiness to have sex as well as their understanding of consent.

Constructs addressed: Observational Learning;

Subjective Norms

(Duration 5:11: $\mathrm{min}$ )
"It's neat how the parents took a very casual approach while talking about abstinence. Not being preachy and being realistic were also two important approaches discussed in the video that I approved of."-Brandon, father of $17 \mathrm{y} / \mathrm{o}$ gay child

"The parent-parent conversation was good. Being surrounded by others who support your view of talking about sex with your kids has to help."-Robert, father with $19 \mathrm{y} /$ o gay son

\section{Reassuring Conversations}

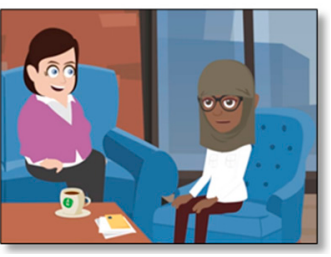

Mean: $5.00(0.63)$

Range: 4-6
Describes potential ways parents can show support to sons who are facing discrimination at school, from extended family members, or in other social spaces.

Constructs addressed: Subjective Norms; Observational Learning (Duration: 4:35 $\mathrm{min}$ )
"Great video. I wouldn't change anything." -Amy, mother of $22 \mathrm{y} / \mathrm{o}$ gay child "After watching I took away a few of the points such as making it clear that I can be relied upon and showing my love during our conversations." - Brandon, father with a $17 \mathrm{y} / \mathrm{o}$ gay son

"I think one of the most important things discussed was getting rid of the stigma around HIV and testing. The information was clear, straight to the point, and easy to

\section{Demystifying HIV Testing}

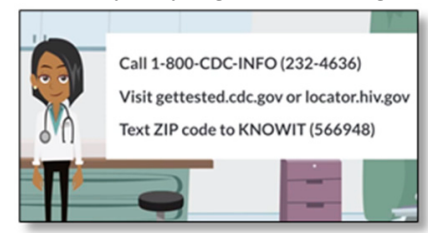

Mean: $5.38(0.52)$

Range: 5-6
Provides information on HIV testing including LGBTQ-friendly testing. Models ways parents can bolster their sons' autonomy in navigating sexual health care structures. Constructs addressed: Attitudes; Intentions (Duration: 4:53)
understand."-Jack, father with a 15 y/o gay son

"This is a much harder topic to discuss with our kids. This video is really good. I do think that being part of the LGBT community, my son probably hears more on this topic that straight, cisgender boys, which is really good

Again, my favorite part was the example conversation the mom had with he son."-Jennifer, mother of $18 \mathrm{y} / \mathrm{o}$ bisexual child 
Table 4. Cont.

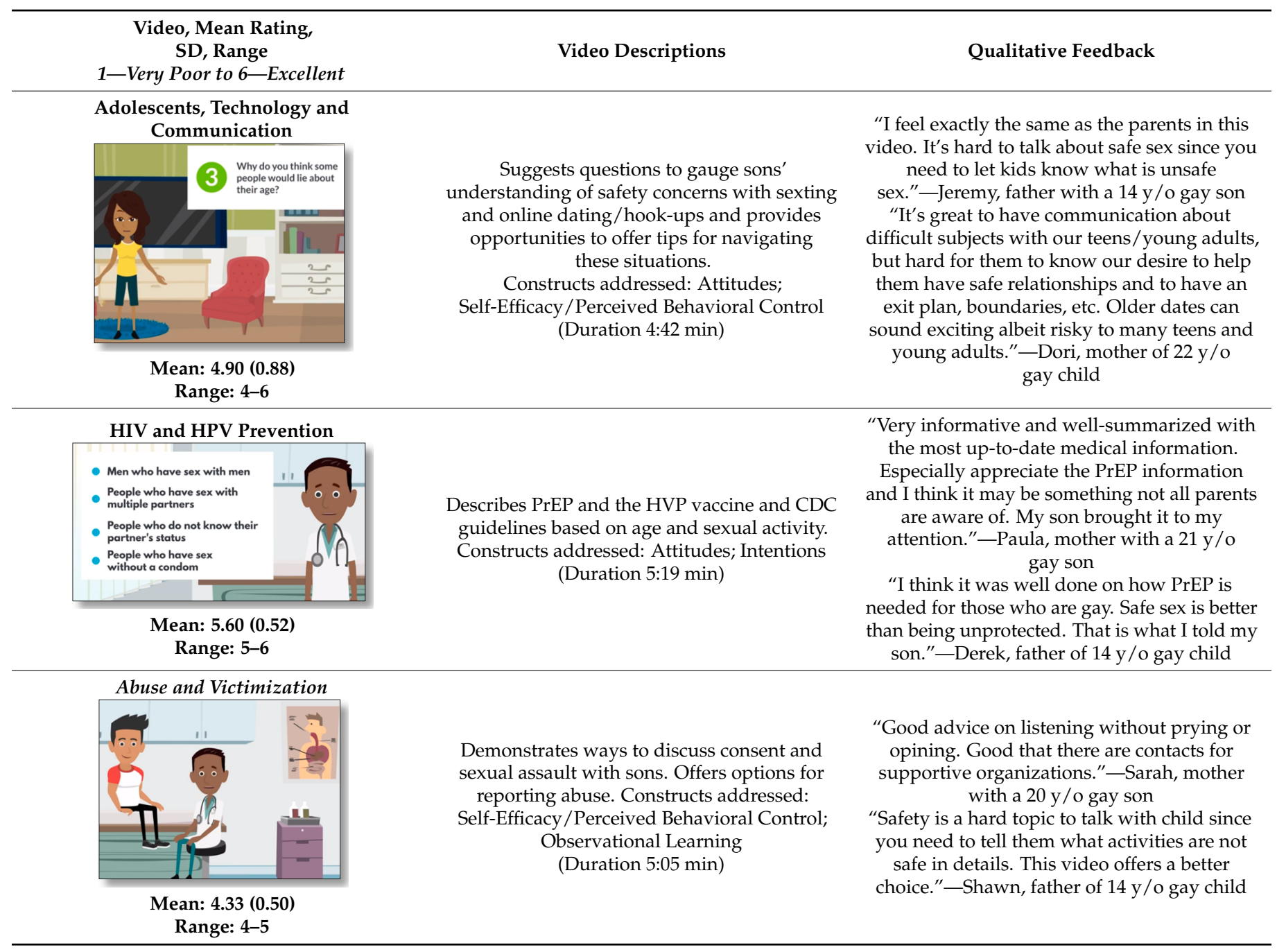

\subsection{Overall Impressions of Parents ASSIST}

Six parents who provided the highest and lowest survey ratings were contacted to view the remaining Parents ASSIST videos they had not seen and to participate in oneon-one interviews. All 6 parents agreed to participate. Interviewed via Zoom, most of the parents $(n=4)$ were recruited online when they saw the study flyers on social media, while 2 of them were referred to the study through snowball sampling. After being granted access to all 13 of the videos and being asked to watch the video series in its entirety, participants were asked about their general impressions of Parents ASSIST, the website, and its format and content. The 30-60 min post-survey interviews were transcribed and thematically organized according to positive and negative impressions with corresponding codes assigned to each unique comment. These positive and negative impressions from parents are listed in Table 5. 
Table 5. Parental Feedback on the Parents ASSIST video series $(n=6)$.

Theme

Step-by-step instructions $(n=15)$ *. Parents appreciated the methodical way each video broke down a communication process or provided basic information about a topic first before building up to more complex issues. The numerous "sample scripts" parents can use in their everyday lives were regarded as one of the tangible benefits to watching both sets of videos.

Short video duration for self-paced viewing and schedule flexibility $(n=8)$. With 12 of the 13 videos running under 5 min viewing time, parents felt they could watch the videos at their own pace based on their level of knowledge (beginner vs. advanced level).They could also anticipate seeing the entire series at different times depending on their schedule due to the unstructured time commitment.

Normalized parental struggles with non-judgmental approach $(n=8)$. Many parents appreciated how the videos recognized the overwhelming nature of discussing sensitive sexual health matters with GBQ sons. The reassuring tone throughout the videos that did not judge parents for not having already initiated talks or have a comprehensive understanding of LGBTQ health created a friendly atmosphere to learn.

Diversity of characters and spectrum of family experiences and conundrums $(n=9)$. Viewers positively regarded the diverse range of animated characters along with the different situations depicted in the videos as seemingly realistic. Parents found the series inclusive of different ethnic/racial individuals with relatable plot lines.

Easy website navigability with apt titles, descriptions, and resources $(n=16)$. Noting the "clean" layout with ample white space, parents overwhelmingly had no issues exploring the Parents ASSIST website and selecting the videos that interested them based on the titles and descriptions. Parents noted the comprehensive topic-specific resources embedded at the end of each video as well as the broad online links listed on the "Resources" tab of the website.

Positive Impressions

Compendium of parenting tips for improved communication $(n=5)$. Parents appreciated the extensiveness of communication tips they heard in the videos, which repeated the value of making up for lost sex talk opportunities, admitting knowledge limitations, and partnering with sons to look up LGBTQ-specific information parents might not have ready answers about.

Acknowledgment that GBQ sons may sometimes know more than parents $(n=3)$. Noting that youth typically come out to parents after they reach a certain level of comfort with being GBQ, several parents appreciated the recognition that sons often possess more knowledge than their parents do about LGBTQ health issues. Videos that depict sons as informed about rudimentary issues pertaining to their own health were favorably received and evaluated as realistic.

Other Positive Feedback

- $\quad$ Addressed misconceptions about GBQ sexuality and barriers to talking about sex;

- Showed a good range of typical family settings (e.g., in a car, playground, health clinic, school);

- Covered the importance of nonverbal communication such as facial expressions, pauses, and head nods;

- $\quad$ Provided reminders to fact-check what sons claim to know about certain issues;

- Information came from an interdisciplinary team of health experts.

Broad focus and undefined youth age targets $(n=3)$. Two parents commented on the vast number of topics covered throughout the series that they judged may be too advanced for parents with elementary-age GBQ sons (e.g., PrEP) or too basic for those with sons already in high school or about to go to college (e.g., what the acronym LGBTQ means). These parents suggested clearly identifying the target age range for each video to help plan for when they would be most appropriate to use.

Idealized or unrealistic dialogue $(n=3)$. Two parents reported some of the dialogue they heard as too idealistic, formal, or unrealistic. According to them, youth depicted in the videos seem to speak maturely while most parents in real life would be unable to deliver some of the recommended lines as they seemed too scripted.

Technical glitches $(n=3)$. Two parents reported experiencing occasional difficulty viewing the videos on their Android phones or tablets. According to them, some videos took a while to load and some of the descriptions did not line up to the appropriate video image.

Negative Impressions
Lack of content addressing lesbian and bisexual daughters and transgender children $(n=5)$. A few parents noted that they would have appreciated videos that tackled gender-specific issues (e.g., use of pronouns, transgender health, etc.) or included concerns of families with lesbian or bisexual daughters.

\section{Other Negative Feedback}

- Lack of single-parent households in the videos;

- Lack of guidance on sexuality health talks prior to a child's coming out

- $\quad$ Need for local-level resources parents can access in their communities;

- Overemphasis on harm reduction and risk mitigation with no mention of advising GBQ youth to completely abstain from certain behavior (e.g., sexting)

${ }^{*} n=$ the number of times a code was mentioned by participants.

\section{Discussion}

There is a growing cohort of U.S. parents who are accepting and supportive of their GBQ sons with same-sex attractions, behaviors, or identities. Given the continued exclusion of this subpopulation's sexual health concerns in school-based sex education programs, parents may be an untapped HIV/STI sexual health resource. The Parents ASSIST videos are a parent-child sex communication intervention iteratively co-developed with extensive 
community input with key stakeholders and expert groups. To our knowledge, this study is one of the first to test an inclusive sex communication intervention that addresses a longstanding health disparity issue associated with this youth population. Our study established the feasibility of enrolling parents of GBQ youth into an online study about targeted sexual health discussions at home and to measure the acceptability of animated videos as a means to learn about GBQ-specific topics and communication skills.

Preliminary findings from this pilot study indicate that parents of GBQ males have a high likelihood of participating in online educational interventions that use animation technology. Among parents recruited, 44\% were fathers, which indicates high interest on the topic not just among mothers who have traditionally been the parent who engages in these conversations [24]. More than half of participants had GBQ sons in high school and, despite most of the sons having come out to their parents more than 2 years ago, parents reported high interest and use for the intervention, which reflects the lack of resources around inclusive sexual health parenting [31]. Most parents viewed the three required videos in a single sitting and responded to our pop-up questions. Additionally, a third of the sample indicated interest in participating in future Parents ASSIST research after completing the surveys. Other parents indicated willingness to be contacted for other similar studies after they completed the consent forms. These promising findings suggest that a series of animated videos about topics pertinent to sexuality, health, and inclusive communication skills is a feasible way to reach parents who would like to be sexual health resources for their GBQ sons.

The acceptability of the intervention was high among the study participants, with parents overwhelmingly endorsing the animated videos across six domains. A majority of the parents could relate to the characters and stories depicted, and most found the videos interesting and realistic. An overwhelming number of participants liked how the main characters responded to the communication situations presented and envisioned their friends as liking these videos as well. From the surveys, parents indicated that the videos increased their knowledge about sexual health issues they can communicate with their sons. Likewise, there was general agreement among participants that if made available, they would recommend the animated series to other parents of GBQ males, as they could see how it would result in initiating and sustaining sexual health discussions. Taken together, the high acceptability ratings across the six domains indicate positive parental attitudes to the intervention medium. In particular, the repeated endorsements of the videos to friends or other parents of GBQ males signal how Parents ASSIST may be a mechanism to influence subjective norms to engage in sexuality-specific sexual heath communication. Given the parental fear that talking about sex with youth may encourage adolescent sexual experimentation $[45,46]$, participants' endorsements of the videos to other parents may indicate a readiness to change subjective norms or larger normative beliefs within the ecological settings that these parent-child dyads navigate. Finally, with parents attesting to an increase in their knowledge level about GBQ-specific sexual health information and a high likelihood of initiating and sustaining inclusive discussions with their GBQ sons, participants' behavioral control or self-efficacy to engage in inclusive talks appears to have similarly increased.

Several limitations have to be noted. First, the pilot survey employed a self-selected group of parents who were recruited mainly through online groups formed around supporting LGBTQ adolescents. While parental acceptance of a GBQ child does not necessarily translate to health communication proficiency, parents in these online groups may be primed to favorably view resources focused on the needs of this youth population. Correspondingly, the views of parents who may be unaccepting of a son's disclosure as GBQ may not be represented in our sample. Additionally, the lack of a randomized comparison group in our study design prohibits establishing intervention efficacy. Similarly, the lack of a pre-test does not allow us to examine changes in theoretical constructs at this time. As such, we are currently limited in our ability to claim Parents ASSIST's capacity to educate parents and encourage inclusive sexual health communication. As a next step, we will 
be conducting a randomized controlled trial (RCT) to assess the videos' efficacy across multiple time points. Finally, a majority of our sample was White and non-Latinx, which also limits the generalizability of our findings.

Content-wise, we note the lack of representation of single-parent households in our videos. While almost half of our participants were fathers, the omission of single-parent households in the videos was pointed out as contributing to an idealistic representation of family discussions around inclusive sexual health. Similarly, while the focus of this study was on parents addressing the sexual health needs of cisgender GBQ males, our exclusion of gender diverse youth and cisgender lesbian, bisexual, and queer females parallel concerns was noted by participants as a shortcoming. Our future work will include more types of family structures beyond the nuclear family and will represent other members of the LGBTQ community in the videos and health discussions. Finally, we will solicit the feedback of the GBQ youth themselves whose parents will participate in the RCT. Differences in youth and parent PCSC reports have been noted in prior studies [47], and we anticipate that GBQ youth may similarly offer a different perspective on the intervention's efficacy in the home.

To conclude, Parents ASSIST was designed to be an online resource for parents to learn about topics germane to the sexual health of GBQ youth and to provide communication skills centered on inclusive parent-child sex communication. Findings from the study support animated videos as a feasible way of learning communication skills and sexual health for parents of GBQ males. The quality of the feedback from parents indicates an unmet need for sexuality-focused family resources tailored to the unique considerations of emerging adolescent males with same-sex attractions, behaviors, and identities. The implications of our findings may be extended to intervention work involving families with LGBTQ children.

Author Contributions: Conceptualization, D.D.F., A.R., A.V. and J.B.; methodology, D.D.F., T.K., A.V. and J.B.; formal analysis, D.D.F. and J.B.; investigation, D.D.F., K.H., A.R., J.C., S.W., T.K., A.V. and J.B.; resources, D.D.F., A.V. and J.B.; data curation, D.D.F.; writing—original draft preparation, D.D.F., K.H., A.R., J.C., S.W., T.K., A.V. and J.B.; writing-review and editing, D.D.F., K.H., A.R., J.C., S.W., T.K., A.V. and J.B.; project administration, D.D.F. and A.R.; funding acquisition, D.D.F. All authors have read and agreed to the published version of the manuscript.

Funding: We would like to acknowledge funding support from the Alex and Rita Hillman Family Foundation Emergent Innovation Grant, the University Research Foundation from University of Pennsylvania Office of the Vice Provost for Research, and the Research Education Institute for Diverse Scholars Program (R25MH087217).

Institutional Review Board Statement: The study was conducted in accordance with the Declaration of Helsinki, and approved by the Institutional Review Board (or Ethics Committee) of the University of Pennsylvania (Protocol 832650, Approved on 25 February 2019) for studies involving humans.

Informed Consent Statement: Informed consent was obtained from all subjects involved in the study.

Data Availability Statement: The data are not publicly available at this time due to ongoing analyses.

Acknowledgments: This work was made possible through the contributions of individuals who comprised our Parent Advisory Board and the Interprofessional Group of Nurses and Health Educators. We are also thankful to the multiple LGBTQ-serving nonprofit organizations such as PFLAG chapters throughout Delaware, New Jersey, and Pennsylvania who assisted extensively in participant recruitment.

Conflicts of Interest: The authors declare no conflict of interest. 


\section{References}

1. Centers for Disease Control and Prevention. HIV and Youth. April 2020. Available online: https://www.cdc.gov/hiv/group/ age/youth/index.html (accessed on 20 March 2021).

2. Centers for Disease Control and Prevention. HIV Surveillance Report, 2018 (Updated). 2018. Available online: https://www.cdc. gov/hiv/pdf/library/reports/surveillance/cdc-hiv-surveillance-report-2018-updated-vol-31.pdf (accessed on 20 March 2021).

3. Centers for Disease Control and Prevention. Youth Risk Behavior Survey: Data Summary \& Trend Reports 2009-2019. 2019. Available online: https: / www.cdc.gov/healthyyouth/data/yrbs/pdf/YRBSDataSummaryTrendsReport2019-508.pdf (accessed on 20 March 2021).

4. Agnew-Brune, C.B.; Balaji, A.B.; Mustanski, B.; Newcomb, M.E.; Prachand, N.; Braunstein, S.L.; Brady, K.A.; Hoots, B.E.; Smith, J.S.; Paz-Bailey, G.; et al. Mental health, social support, and HIV-related sexual risk behaviors among HIV-negative adolescent sexual minority males: Three U.S. cities, 2015. AIDS Behav. 2019, 23, 3419-3426. [CrossRef] [PubMed]

5. Ivey-Stephenson, A.Z.; Demissie, Z.; Crosby, A.E.; Stone, D.M.; Gaylor, E.; Wilkins, N.; Lowry, R.; Brown, M. Suicidal ideation and behaviors among high school students-Youth Risk Behavior Survey, United States, 2019. MMWR Suppl. 2020, 69, 47-55. [CrossRef]

6. Jones, J.M. LGBT Identification Rises to 5.6\% in Latest U.S. Estimate. Gallup. 21 February 2021. Available online: https: / / news.gallup.com/poll/329708/lgbt-identification-rises-latest-estimate.aspx (accessed on 25 March 2021).

7. Twenge, J.M.; Sherman, R.A.; Wells, B.E. Changes in American adults' reported same-sex sexual experiences and attitudes, 1973-2014. Arch. Sex. Behav. 2016, 45, 1713-1730. [CrossRef] [PubMed]

8. Grov, C.; Rendina, H.J.; Parsons, J.T. Birth cohort differences in sexual identity development milestones among HIV-negative gay and bisexual men in the United States. J. Sex Res. 2018, 55, 984-994. [CrossRef]

9. McKay, E.A.; Fontenot, H.B. Parent-adolescent sex communication with sexual and gender minority youth: An integrated review. J. Pediatr. Health Care 2020, 34, e37-e48. [CrossRef]

10. Mills-Koonce, W.R.; Rehder, P.D.; McCurdy, A.L. The significance of parenting and parent-child relationships for sexual and gender minority adolescents. J. Res. Adolesc. 2018, 28, 637-649. [CrossRef] [PubMed]

11. Newcomb, M.E.; LaSala, M.C.; Bouris, A.; Mustanski, B.; Prado, G.; Schrager, S.M.; Huebner, D.M. The unfluence of families on LGBTQ youth health: A call to action for innovation in research and intervention development. LGBT Health 2019, 6, 139-145. [CrossRef]

12. Flores, D.D.; Docherty, S.L.; Relf, M.V.; McKinney, R.E.; Barroso, J.V. “It's Almost Like Gay Sex Doesn't Exist”: Parent-Child Sex Communication According to Gay, Bisexual, and Queer Male Adolescents. J. Adolesc. Res. 2019, 34, 528-562. [CrossRef] [PubMed]

13. Flores, D.D.; Abboud, S.; Barroso, J. Hegemonic Masculinity during Parent-Child Sex Communication with Sexual Minority Male Adolescents. Am. J. Sex. Educ. 2019, 14, 417-439. [CrossRef] [PubMed]

14. Herek, G. A Nuanced View of Stigma for Understanding and Addressing Sexual and Gender Minority Health Disparities. LGBT Health 2016, 3, 397-399. [CrossRef]

15. LaSala, M.C. Condoms and connection: Parents, gay and bisexual youth, and HIV risk. J. Marital. Fam. Ther. 2015, 41, 451-464. [CrossRef] [PubMed]

16. Coakley, T.M.; Randolph, S.; Shears, J.; Beamon, E.R.; Collins, P.; Sides, T. Parent-youth communication to reduce at-risk sexual behavior: A systematic literature review. J. Hum. Behav. Soc. Environ. 2017, 27, 609-624. [CrossRef]

17. Hadley, W.; Brown, L.K.; Lescano, C.M.; Kell, H.; Spalding, K.; Diclemente, R.; Donenberg, G. Parent-adolescent sexual communication: Associations of condom use with condom discussions. AIDS Behav. 2009, 13, 997-1004. [CrossRef]

18. Hall, K.S.; Moreau, C.; Trussell, J. Associations between sexual and reproductive health communication and health service use among U.S. adolescent women. Perspect. Sex. Reprod. Health 2012, 44, 6-12. [CrossRef]

19. Hutchinson, M.K.; Cederbaum, J.A. Talking to daddy's little girl about sex: Daughters' reports of sexual communication and support from fathers. J. Fam. Issues 2011, 32, 550-572. [CrossRef]

20. Kapungu, C.T.; Baptiste, D.; Holbeck, G.; McBride, C.; Robinson-Brown, M.; Sturdivant, A.; Crown, L.; Paikoff, R. Beyond the "birds and the bees": Gender differences in sex-related communication among urban African-American adolescents. Fam. Process 2010, 49, 251-264. [CrossRef]

21. Widman, L.; Choukas-Bradley, S.; Noar, S.M.; Nesi, J.; Garrett, K. Parent-adolescent sexual communication and adolescent safer sex behavior: A meta-analysis. JAMA Pediatr. 2016, 170, 52-61. [CrossRef]

22. Campero, L.; Walker, D.; Atienzo, E.E.; Gutierrez, J.P. A quasi-experimental evaluation of parents as sexual health educators resulting in delayed sexual initiation and increased access to condoms. J. Adolesc. 2011, 34, 215-223. [CrossRef] [PubMed]

23. Kovar, C.L.; Salsberry, P.J. Does a satisfactory relationship with her mother influence when a 16-year-old begins to have sex? MCN Am. J. Matern. Child Nurs. 2012, 37, 122-129. [CrossRef]

24. Flores, D.D.; Barroso, J. 21st Century Parent-Child Sex Communication in the U.S.: A Process Review. Annu. J. Sex Res. 2017, 54, 532-548. [CrossRef]

25. Rose, I.D.; Friedman, D.B. We need health information too: A systematic review of studies examining the health information seeking and communication practices of sexual minority youth. Health Educ. J. 2012, 72, 417-430. [CrossRef]

26. Bouris, A.; Guilamo-Ramos, V.; Pickard, A.; Shiu, C.; Loosier, P.S.; Dittus, P.; Gloppen, K.; Waldmiller, J.M. A systematic review of parental influences on the health and well-being of lesbian, gay, and bisexual youth: Time for a new public health research and practice agenda. J. Prim. Prev. 2010, 31, 273-309. [CrossRef] [PubMed] 
27. Bregman, H.R.; Malik, N.M.; Page, M.J.; Makynen, E.; Lindahl, K.M. Identity profiles in lesbian, gay, and bisexual youth: The role of family influences. J. Youth Adolesc. 2013, 42, 417-430. [CrossRef]

28. Ryan, C.; Huebner, D.; Diaz, R.M.; Sanchez, J. Family rejection as a predictor of negative health outcomes in white and Latino lesbian, gay, and bisexual young adults. Pediatrics 2009, 123, 346-352. [CrossRef] [PubMed]

29. Ryan, C.; Russell, S.T.; Huebner, D.; Diaz, R.; Sanchez, J. Family acceptance in adolescence and the health of LGBT young adults. J. Child Adolesc. Psychiatr. Nurs. 2010, 23, 205-213. [CrossRef]

30. Morris, E.; Balaji, A.B.; Trujillo, L.; Rasberry, C.N.; Mustanski, B.; Newcomb, M.E.; Brady, K.A.; Prachand, N.G. Family factors and HIV-related risk behaviors among adolescent sexual minority males in three United States cities, 2015. LGBT Health 2020, 7, 367-374. [CrossRef]

31. Rose, I.D.; Friedman, D.B.; Annang, L.; Spencer, S.M.; Lindley, L.L. Health communication practices among parents and sexual minority youth. J. LGBT Youth 2014, 11, 316-335. [CrossRef]

32. LaSala, M.C. Parental influence, gay youths, and safer sex. Health Soc. Work 2007, 32, 49-55. [CrossRef]

33. Newcomb, M.E.; Feinstein, B.A.; Matson, M.; Macapagal, K.; Mustanski, B. "I have no idea what's going on out there": Parents' perspectives on promoting sexual health in lesbian, gay, bisexual, and transgender adolescents. Sex. Res. Soc. Policy 2018, 15, 111-122. [CrossRef] [PubMed]

34. Estes, M.L. 'If there's one benefit, you're not going to get pregnant': The sexual miseducation of gay, lesbian, and bisexual individuals. Sex Roles 2017, 77, 615-627. [CrossRef]

35. Feinstein, B.A.; Thomann, M.; Coventry, R.; Macapagal, K.; Mustanski, B.; Newcomb, M.E. Gay and bisexual adolescent boys' perspectives on parent-adolescent relationships and parenting practices related to teen sex and dating. Arch. Sex. Behav. 2018, 47, 1825-1837. [CrossRef] [PubMed]

36. Thoma, B.C.; Huebner, D.M. Parental monitoring, parent-adolescent communication about sex, and sexual risk among young men who have sex with men. AIDS Behav. 2014, 18, 1604-1614. [CrossRef] [PubMed]

37. Hutchinson, M.K.; Jemmott, J.B., III; Jemmott, L.S.; Braverman, P.; Fong, G.T. The role of mother-daughter sexual risk communication in reducing sexual risk behaviors among urban adolescent females: A prospective study. J. Adolesc. Health 2003, 33, 98-107. [CrossRef]

38. Ajzen, I. From intentions to actions: A theory of planned behavior. In Action Control; Kuhl, J., Beckman, J., Eds.; Springer: Berlin/Heidelberg, Germany, 1985; pp. 11-39.

39. Ajzen, I. The theory of planned behavior. Organ. Behav. Hum. Decis. Process 1991, 50, 179-211. [CrossRef]

40. Bandura, A. Social cognitive theory: An agentic perspective. Annu. Rev. Psychol. 2001, 52, 1-26. [CrossRef] [PubMed]

41. Kreuter, M.W.; Wray, R.J. Tailored and targeted health communication: Strategies for enhancing information relevance. Am. J. Health Behav. 2003, 27, S227-S232. [CrossRef] [PubMed]

42. Schnall, R.; Travers, J.; Rojas, M.; Carballo-Diéguez, A. eHealth interventions for HIV prevention in high-risk men who have sex with men: A systematic review. J. Med. Internet Res. 2014, 16, e134. [CrossRef] [PubMed]

43. Shen, F.; Sheer, V.C.; Li, R. Impact of narratives on persuasion in health communication: A meta-analysis. J. Advert. 2015, 44, 105-113. [CrossRef]

44. Flores, D.D.; Rosario, A.; Bond, K.; Villarruel, A.; Bauermeister, J. Parents ASSIST (Advancing Supportive and Sexuality-Inclusive Sex Talks): Iterative Development of a Sex Communication Video Series for Parents of Gay, Bisexual, and Queer Male Adolescents. J. Fam. Nurs. 2020, 26, 90-101. [CrossRef] [PubMed]

45. Aronowitz, T.; Todd, E.; Agbeshie, E.; Rennells, R.E. Attitudes that affect the ability of African American preadolescent girls and their mothers to talk openly about sex. Issues Ment. Health Nurs. 2007, 28, 7-20. [CrossRef]

46. Meschke, L.L.; Dettmer, K. 'Don't cross a man's feet': Hmong parent-daughter communication about sexual health. Sex Educ. 2012, 12, 109-123. [CrossRef] [PubMed]

47. Flores, D.D.; Meanley, S.; Bond, K.; Agenor, M.; Relf, M.; Barroso, J. Topic Recollections and Recommendations for Inclusive Parent-Child Sex Communication by Gay, Bisexual, and Queer Adolescent Males. Behav. Med. 2021, 47, 175-184. [CrossRef] [PubMed] 